\title{
ANALISIS PENGEMBANGAN JARINGAN KOMPUTER UIN SUNAN KALIJAGA YOGYAKARTA MENGGUNAKAN PERBANDINGAN PROTOKOL ROUTING STATIK DAN ROUTING DINAMIS OSPF
}

\author{
Rahmadhan Gatra*1, Bambang Sugiantoro \\ 1,2 UIN Sunan Kalijaga Yogyakarta \\ Email: ${ }^{1}$ rahmadhan.gatra@uin-suka.ac.id, ${ }^{2}$ bambang.sugiantoro@uin-suka.ac.id \\ *Penulis Korespondensi
}

(Naskah masuk: 31 Desember 2019, diterima untuk diterbitkan: 18 Maret 2021)

\begin{abstract}
Abstrak
Penelitian ini menjelaskan perbandingan routing sebagai salah satu manajemen jaringan komputer. Tujuan penelitian ini adalah melakukan analisis terhadap protokol routing statik dengan routing dinamis OSPF pada jaringan komputer di lingkungan Universitas Islam Negeri Sunan Kalijaga Yogyakarta dengan metode studi literatur dan wawancara dalam pengumpulan data. Penelitian dibuat berdasarkan pemodelan (simulasi) berbasis aplikasi EVE-NG. Performa yang dihasilkan dari perbandingan routing tersebut diukur menggunakan parameter QoS meliputi nilai throughput, packet loss, delay, dan jitter. Pengujian kinerja jaringan menggunakan skenario normal dan skenario sibuk pada routing statik dan routing dinamis OSPF. Hasil penelitian menunjukkan nilai skenario normal throughput untuk routing protokol statik sebanyak 598,10Bps dan nilai untuk OSPF sebanyak 598,34Bps, sedangkan skenario sibuk untuk routing protokol statik sebanyak 598,82Bps dan nilai untuk OSPF sebesar 597,58Bps. Packet loss skenario normal routing protokol statik sebanyak 0,23\% dan nilai untuk OSPF sebanyak $0,27 \%$ serta skenario sibuk untuk routing protokol statik sebanyak $0,24 \%$ dan OSPF sebanyak $0,26 \%$. Nilai delay skenario normal routing statik protokol sebanyak 59,39ms dan nilai untuk OSPF sebanyak 59,36ms, sedangkan skenario sibuk untuk routing protokol statik sebanyak 59,32ms dan nilai untuk OSPF sebanyak 59,44ms. Jitter menggunakan skenario normal protokol routing statik sebanyak 0,98ms dan nilai untuk OSPF sebanyak 0,98ms serta skenario sibuk routing protokol statik sebanyak 0,98ms dan nilai untuk OSPF sebanyak 0,99ms. Berdasarkan Parameter QoS nilai throughput dan delay pada routing statik lebih optimal dibandingkan routing dinamis OSPF untuk skenario sibuk, begitu pula nilai packet loss dan jitter pada routing statik menunjukkan nilai lebih optimal dibandingkan routing dinamis OSPF pada skenario normal dan sibuk.
\end{abstract}

Kata Kunci: Protokol Routing, Statik, OSPF, EVE-NG, dan QoS.

\section{COMPUTER NETWORK DEVELOPMENT ANALYSIS OF UIN SUNAN KALIJAGA WITH COMPARISON OF STATIC ROUTING PROTOCOLS AND OSPF DYNAMIC ROUTING}

\begin{abstract}
This study describes the comparison of routing as one of computer network management. The purpose of this study is to analyze static routing protocols with OSPF dynamic routing on computer networks in the State Islamic University of Sunan Kalijaga Yogyakarta with literature study methods and interviews in data collection. The study was made based on modeling (simulation) based on EVE-NG applications. The performance resulting from the comparison of routing is measured using QoS parameters including the value of throughput, packet loss, delay, and jitter. Network performance testing uses normal scenarios and busy scenarios on static routing and OSPF dynamic routing. The results showed a normal throughput scenario value for static routing protocol as much as 598,10Bps and value for OSPF as much as 598,34Bps, whereas a busy scenario for static protocol routing as much as 598,82Bps and value for OSPF as much as 597,58Bps. Normal packet routing scenario static routing protocol is $0,23 \%$ and $O S P F$ value is $0,27 \%$ and the busy scenario is static protocol routing $0,24 \%$ and OSPF is 0,26\%. The value of delay in the normal static protocol routing scenario is 59,39ms and the value for OSPF is 59,36ms, while the scenarios for busy static protocol routing are 59,32ms and the value for OSPF is 59,44ms. Jitter uses normal static routing protocol scenarios as much as 0,98ms and values for OSPF as much as 0,98ms and busy scenarios as static protocol routing as much as 0,98ms and values for OSPF as much as 0,99ms. Based on QoS parameters, the value of throughput and delay in static routing is more optimal than
\end{abstract}


dynamic OSPF routing for busy scenarios, as well as packet loss and jitter values in static routing shows more optimal values than OSPF dynamic routing in normal and busy scenarios.

Keywords: Routing Protocol, Static, OSPF, EVE-NG, and QoS.

\section{PENDAHULUAN}

Pesatnya pengembangan dalam dunia teknologi dan informasi saat ini menuntut adanya ketepatan, kemudahan dan kecepatan melakukan akses data dan informasi. Ketersediaan terhadap informasi yang cepat, mudah dan tepat akan mengakibatkan kinerja pada sebuah jaringan komputer menjadi meningkat dan akhirnya menyebabkan jaringan komputer akan terganggu jika tidak bisa mengendalikan peningkatan kinerja jaringan komputer tersebut (Gatra, Akbar, Sugiantoro, \& Asyhab, 2019). Disisi lain pendekatan teknologi dalam perkembangannya telah banyak digunakan mereduksi trafik jaringan berkaitan dengan pemanfaatan agen statik dan mobile dalam hal performa jaringan yang berkaitan dengan sistem deteksi penyusupan yang telah berkembang (Sugiantoro, 2017) Untuk dapat berkomunikasi dengan baik antara jaringan lokal atau intranet dengan jaringan luar termasuk internet perlu adanya sebuah mekanisme routing yang digunakan untuk melakukan manajemen jaringan komputer (Muhallim, 2017).

Protokol routing merupakan media dalam melakukan komunikasi data dan informasi antara satu sama lainnya. routing statik dan routing dinamis adalah dua tipe routing protokol yang digunakan dalam jaringan. Routing statik merupakan routing yang terbentuk oleh admin jaringan dengan melakukan konfigurasi secara manual (Ulfa \& Fatoni, 2017). Routing statik lebih mudah digunakan karena perawatan serta troubleshooting relatif lebih mudah, namun ada kelemahan dari routing statis yang terletak pada kemampuan fail over yang tidak dimilikinya, sehingga kalau ada perangkat router yang mati maka aktifitas jaringan juga ikut terhenti (Ardian \& Setiyaningsih, 2014). Kelemahan dari routing statik adalah seorang admin jaringan harus melakukan update routing jika ada penambahan perangkat baru yang memerlukan routing dalam komunikasi jaringan. Penerapan routing statik perlu adanya sebuah parameter Quality of Service (QoS) yang digunakan untuk menganalisis kinerja dari jaringan. Ada beberapa parameter QoS yang digunakan dalam routing statik diantaranya delay, packet loss, throughput, dan jitter (Muhallim, 2017). Delay atau waktu tunda adalah total penjumlahan berbagai waktu tunda dari proses pengiriman data pada jaringan internet (KUSUMA, 2017). Packet loss dapat diterjemahkan sebagai ketidaksuksesan dalam transmisi paket data pada alamat yang dituju dan menyebabkan ada beberapa paket data dalam jangka waktu pengiriman tersebut hilang atau lost
(KUSUMA, 2017). Throughput merupakan total jumlah data yang dikirim dalam interval tertentu dibagi waktu pengiriman data (Iskandar \& Hidayat, 2015). Jitter merupakan variasi delay yang diterima pada panjang antiran paket data (Muhallim, 2017). Dalam penerapan pengujian kinerja jaringan routing statik berdasarkan parameter QoS banyak digunakan sebagai pengukuran performa throughput downstream dan upstream untuk waktu upload dan download dengan media aplikasi ping menggunakan protokol ICMP pada loadbalancing yang memiliki nilai baik (Ardian \& Setiyaningsih, 2014). Pengukuran tingkat keunggulan performa upload dan download dalam streaming video dengan protokol UDP pada IPv4 dan IPv6 menunjukkan nilai delay IPv6 lebih baik untuk file $10 \mathrm{Mb}$ bernilai 0.024 dan nilai delay IPv4 untuk file $10 \mathrm{Mb}$ bernilai 0.04 (Ulfa \& Fatoni, 2017).

Hal terpenting dalam penentuan routing dinamis, selain protokol adalah topologi jaringan yang akan diterapkan juga sangat berpengaruh dalam proses pengiriman data, apakah dapat diterima dengan cepat atau lambat, bahkan diterima secara utuh, rusak atau tidak sampai sama sekali (Argenta, 2016). Salah satu routing yang saat ini banyak digunakan diantaranya routing dimanis dengan berbagai macam protokol routing seperti Open Short Path First (OSPF)(Sulaiman \& Ihwani, 2017). OSPF merupakan hasil dari algoritma dijstra sebagai penentu jalur terbaiknya dalam pencarian rute terpendek dengan menggunakan simpul-simpul sederhana untuk mencapai router atau alamat tujuan pada jaringan (Ardyansah, Irfan A, \& Rachman, 2018). Dengan menggunakan routing protokol OSPF maka sebuah jaringan yang sudah terhubung tidak akan mengakibatkan looping, karena jalur utama dan terbaik telah dipilih dan jalur lainnya menjadi jalur cadangan, sehingga jika jalur utama mengalami gangguan maka jalur cadangan akan mengambil alih fungsi jalur utama (Sulaiman \& Ihwani, 2017). Penerapan routing dinamis OSPF sama seperti routing statik dalam metode atau parameter untuk mencari kinerja jaringannya.

Muhallim (2017) pernah melakukan penelitian tentang perbandingan protokol routing statik dan OSPFv2 di jaringan komputer Universitas Andi Djemma. Penelitian tersebut merancang dengan simulator GNS3 dengan 4 (empat) perangkat router dengan penerapan topologi mesh. Proses pengujian dilakukan dengan menggunakan skenario normal dan sibuk dengan mengambil data antara 100 bytes sampai 1000 bytes, kemudian dilakukan pengujian sebanyak 60 kali dalam satu kali pengiriman. Penelitian tersebut menyimpulkan bahwa OSPF dapat memperpendek proses routing dibanding 
routing statik dengan hasil throughput routing OSPF untuk skenario normal sebesar 568,63Bps dan statik sebesar 565,63Bps. Sedangkan untuk skenario sibuk untuk OSPFv2 sebesar 514,48Bps dan statik sebesar 515,11Bps dengan packet loss untuk kedua jenis jaringan sebesar 0\% (Muhallim, 2017).

Berdasarkan penelitian sebelumnya, peneliti melakukan analisis perbandingan topologi star untuk routing protokol statik dan dinamis OSPF yang ada di UIN Sunan Kalijaga Yogyakarta dengan menggunakan parameter QoS untuk melihat perbandingan nilai throughput, nilai packet loss, nilai delay dan nilai jitter

\section{METODE PENELITIAN}

Tahapan yang dikerjakan dalam penelitian ini terlihat pada Gambar 1.

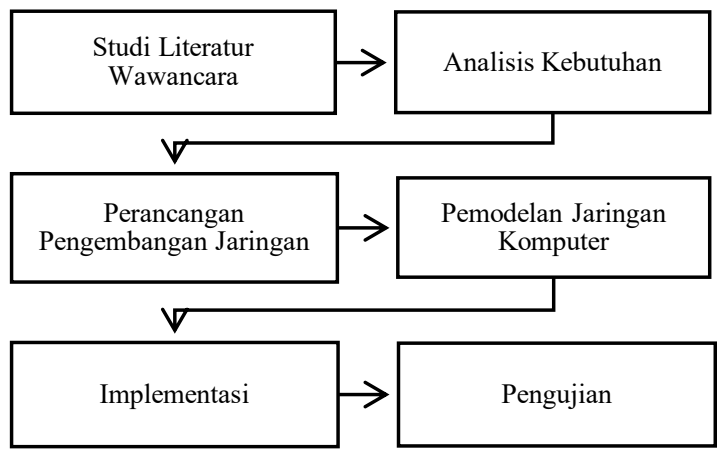

Gambar 1 Bagan tahapan proses penelitian

\subsection{Studi Literatur dan Wawancara}

Pengumpulan data dilakukan di UIN Sunan Kalijaga Yogyakarta. Kegiatan pengumpulan data dilakukan dengan studi literatur dan wawancara. Studi literatur merupakan salah satu bagian yang dipakai dalam pengumpulan data dan informasi dari sumber-sumber yang berhubungan dengan tema yang sedang diteliti seperti jurnal ilmiah, bukubuku, dan sumber informasi online dari internet. Kemudian peneliti merangkum literasi tersebut dan mengelompokkannya sesuai tema.

Adapun wawancara dilakukan dengan mewawancarai langsung pihak terkait bidang jaringan komputer yakni UPT. PTIPD UIN Sunan Kalijaga Yogyakarta sebagai Unit Pelayanan Teknis terkait dengan masalah IT termasuk jaringan komputer. Beberapa responden yang diwawancara meliputi Kepala UPT. PTIPD UIN Sunan Kalijaga, Analis Sistem Informasi dan Pranata Komputer Ahli Pertama.

Semua informasi yang diperoleh dan dicatat terkait informasi mengenai penggunaan routing statik dan routing dinamis OSPF, manajemen IP Address, manajemen routing dan network area routing OSPF, serta manajemen konfigurasi lainnya termasuk manajemen Virtual Local Area Network (VLAN) dan Virtual Transport Protocol (VTP) yang selanjutnya dilakukan tahapan analisis terhadap kebutuhan, perancangan dan pemodelan desain topologi serta Implementasi penerapan konfigurasi dan pengujian kinerja jaringan komputer.

\subsection{Analisis Kebutuhan}

Tahapan analisis kebutuhan penelitian dalam hal pengembangan jaringan meliputi data dan informasi termasuk perangkat keras dan perangkat lunak yang berfungsi UIN Sunan Kalijaga Yogyakarta.

Adapun kebutuhan perangkat keras dalam proses pemodelan pengembangan jaringan sebagai berikut:

1. Processor computer merk Intel $\AA^{\circledR}$ Core $^{\mathrm{TM}}$ i77500U CPU@2.70GHz (4 CPUs), 2.9GHz

2. Memory (RAM) 8GB

3. Hard drive $1 \mathrm{~TB}$

Sedangakan kebutuhan perangkat lunak dalam pengukuran kinerja jaringan protokol routing statik dan routing dinamis OSPF untuk proses pemodelan pengembangan jaringan penelitian ini sebagai berikut:

1. Operating System Windows 10 Home single language 64-bit (10.0, Build 17763)

2. Aplikasi Emulated Virtual Environment Next Generation (EVE-NG)

3. Aplikasi Wireshark

4. Aplikasi PING

5. Aplikasi Microsoft Excel (digunakan untuk membantu dalam perhitungan data dari aplikasi wireshak)

\subsection{Perancangan Pengembangan Jaringan}

Tahapan yang lakukan dalam mengembangkan sebuah jaringan komputer adalah membuat rancangan desain topologi jaringan komputer. Tahap perancangan dilakukan untuk menekan sekecil mungkin kesalahan pada proses membangun dan mengembangkan jaringan. Tahap perancangan pengembangan jaringan akan menghasilkan sebuah prototype topologi atau desain jaringan yang kemudian dilakukan konfigurasi sehingga dapat berjalan dengan baik. Selanjutnya akan dilakukan pengujian berdasarkan skenario yang telah ditentukan yaitu skenario normal dan sibuk

\subsection{Pemodelan Jaringan Komputer}

Tahapan selanjutnya dalam pengembangan jaringan komputer adalah melakukan pemodelan. Tahapan ini peneliti mengerjakan pembuatan pemodelan jaringan dengan aplikasi Emulated Virtual Environment Next Generation (EVE-NG). 
Tujuan dari pengaplikasian pemodelan dengan jaringan menggunakan EVE-NG selain untuk meminimalisir biaya yang ditimbulkan juga meminimalisir kerusakan dan gangguan dari hardware atau perangkat keras maupun dari faktor brainware/human eror (manusia atau pengguna) dan alam.

\subsection{Implementasi}

Setelah dilakukan proses perancangan dan pemodelan topologi jaringan untuk pengembangan jaringan komputer. Tahapan selanjutnya yang dilakukan adalah implementasi. Rancangan sebuah topologi yang diimplementasikan membutuhkan sebuah konfigurasi interface dan protokol routing pada routing statik dan routing dinamis OSPF berdasarkan IP address dan routing yang sudah dilakukan pada tahap perancangan pengembangan jaringan sebelumnya.

\subsection{Pengujian}

Tahapan terakhir dalam penelitian ini adalah melakukan pengujian terhadap implementasi dari jaringan yang telah terbentuk. Tahapan Pengujian dilakukan untuk mengetahui jalan kerja yang dihasilkan dari sebuah jaringan. Salah satu cara yang digunakan dalam melakukan pengujian yaitu perintah PING pada berbasis command line interface pada aplikasi Command Prompt (CMD). Proses pengujian dimulai dengan pengiriman protokol ICMP dari komputer sumber/awal pada perangkat yang dituju bisa berupa komputer, server, atau perangkat lainnya yang mempunyai kemampuan dalam jaringan. Selanjutnya dilakukan analisis pengujian hasil kinerja dari perintah PING menggunakan aplikasi wireshark untuk setiap parameter yang diujikan. Adapun besaran ukuran pengiriman paket data antara 100 bytes sampai 1000 bytes dengan menggunakan dua skenario pengujian yang telah ditentukan dengan lama pengujian sebanyak 60 kali dengan sampling zona yang telah ditentukan. Pengujian hasil kinerja jaringan komputer tersebut dituliskan dalam bentuk nilai throughput, nilai delay, nilai jitter dan nilai packet loss (KUSUMA, 2017).

Pada penelitian ini terdapat dua skenario yang dilakukan dalam pengambilan data yaitu skenario pertama saat kondisi jaringan normal. Kemudian pada skenario ke dua dilakukan saat kondisi jaringan sibuk. Pada kondisi jaringan normal komputer client melakukan pengiriman paket data hanya pada client yang akan diambil datanya. Sedangkan pada kondisi kedua, jaringan komputer client melakukan pengiriman paket data pada client yang akan diambil datanya dengan beberapa client lainnya bertugas melakukan pengiriman paket data ke client yang akan diambil datanya. Kondisi ini membuat jaringan menjadi sibuk, selanjutnya hasil pengujian dilakukan dengan mengukur paket data yang dikirim. Kemudian dilakukan perhitungan dan pengelompokan berdasarkan ukuran data saat pengujian yang kemudian diambil rata-ratanya.

\section{HASIL DAN PEMBAHASAN}

\subsection{Topologi Existing Jaringan Komputer}

Pengembangan implementasi routing pada jaringan komputer di UIN Sunan Kalijaga Yogyakarta banyak mengalami transformasi mengikuti kemajuan teknologi meliputi jumlah gedung yang bertambah menyebabkan perangkat jaringan menjadi bertambah sehingga perangkat jaringan tersebut harus dapat mensupport kelancaran lalu lintas data dalam sebuah jaringan komputer. Topologi existing jaringan komputer pada saat menggunakan routing statik dan routing dinamis masih memakai topologi star seperti terlihat pada Gambar 2 dan Gambar 3

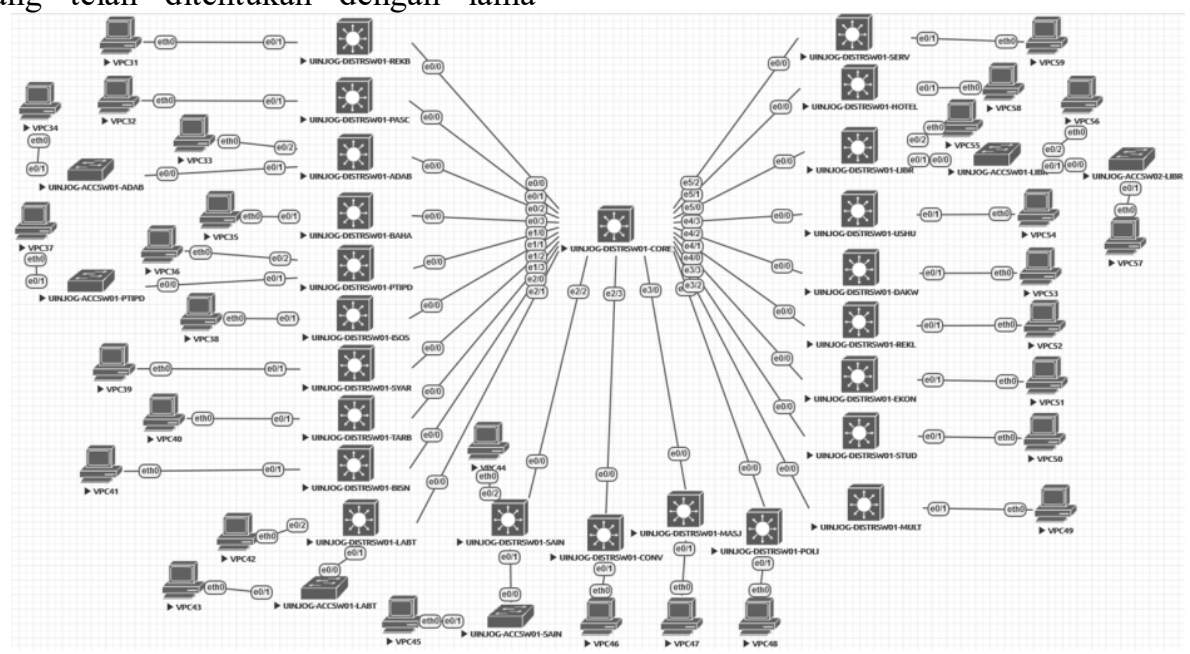

Gambar 2 Topologi existing jaringan komputer UIN Sunan Kalijaga Yogyakarta menggunakan routing statik 


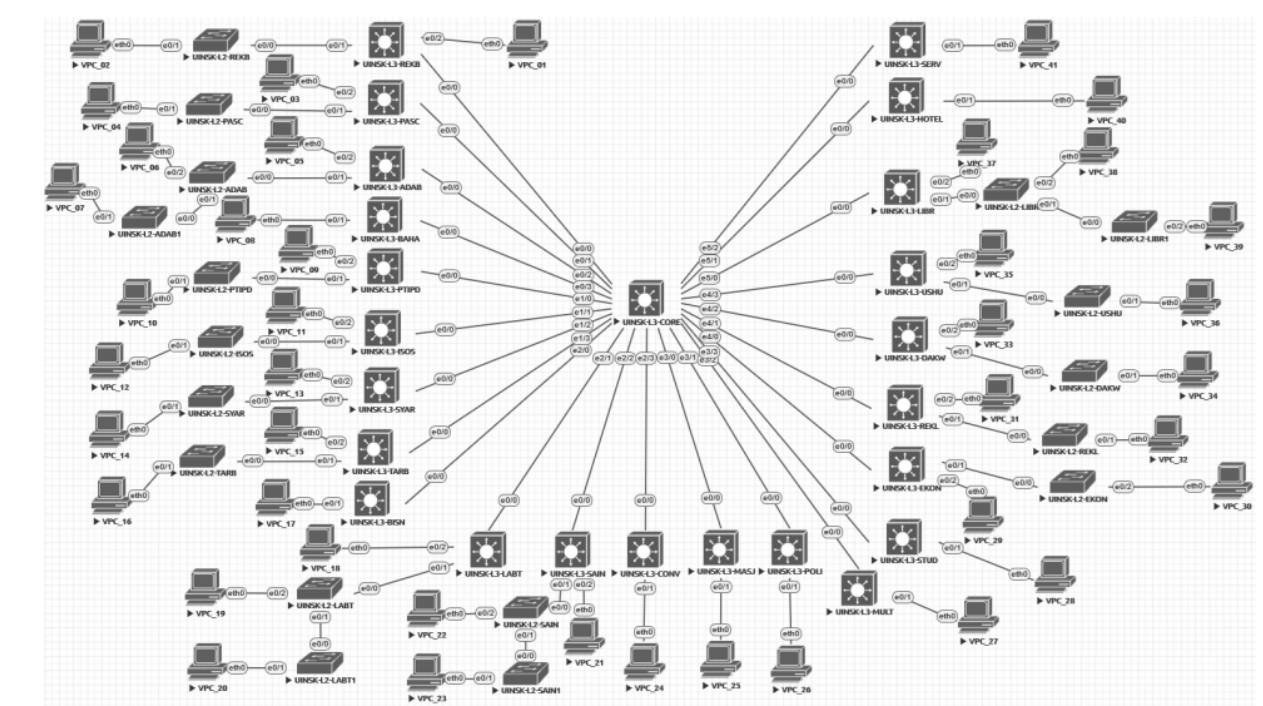

Gambar 3 Topologi existing jaringan komputer UIN Sunan Kalijaga Yogyakarta menggunakan routing dinamis OSPF

\subsection{Pengujian Quality of Services}

Teknik pengelolaan terhadap pengukuran hasil nilai dari parameter Quality of Services meliputi nilai throughput, nilai delay, nilai jitter, dan paket loss dalam sebuah jaringan. Dengan Quality of Services dapat membantu admin jaringan dalam optimalisasi kinerja sebuah jaringan yang saling terkoneksi (Iskandar \& Hidayat, 2015). Quality of Services dapat mendefinisikan karakteristik kinerja dari sebuah jaringan komputer secara kuantitatif maupun kualitatif (ISKANDAR \& HIDAYAT, 2015). Berikut ini parameter Quality of Service yang digunakan, antara lain (TIPHON, 1999):

\section{a. Nilai Throughput}

Nilai Throughput adalah total jumlah data yang dikirim dalam interval tertentu dibagi waktu pengiriman data (Iskandar \& Hidayat, 2015). Rate transfer data efektif dapat diukur dalam format waktu bit per second (bps) (KUSUMA, 2017). Persamaan perhitungan nilai throughput, sebagai berikut:

$$
\text { Throughput }=\frac{\text { Total paket data dikirim }}{\text { waktu pengiriman paket data }}
$$

\section{b. Nilai Packet Loss}

Packet loss dapat diterjemahkan sebagai ketidaksuksesan dalam transmisi paket data pada alamat yang dituju dan menyebabkan ada beberapa paket data dalam jangka waktu pengiriman tersebut hilang atau lost (KUSUMA, 2017). Berikut ini rumus persamaan perhitungan nilai packet loss.

$$
\text { Packet loss }=\frac{\text { paket dikirim }- \text { paket diterima }}{\text { paket dikirim }} \times 100 \%
$$

Ketegori capaian kinerja nilai packet loss untuk lebih jelas lihat Tabel 1.
Tabel 1 Kategori capaian nilai Packet Loss menurut Tiphon

\begin{tabular}{ccc}
\hline $\begin{array}{c}\text { Kategori } \\
\text { Nilai }\end{array}$ & $\begin{array}{c}\text { Kategori } \\
\text { Persentasi }\end{array}$ & $\begin{array}{c}\text { Kategori } \\
\text { Capaian }\end{array}$ \\
\hline 4 & $0 \%$ & Excellent \\
3 & $3 \%$ & Good \\
2 & $15 \%$ & Medium \\
1 & $25 \%$ & Poor \\
\hline
\end{tabular}

\section{c. Nilai Delay}

Delay atau waktu tunda adalah total penjumlahan berbagai waktu tunda dari proses pengiriman data pada jaringan internet (KUSUMA, 2017). Persamaan perhitungan delay, sebagai berikut:

Total delay $=$ $\sum$ waktu paket diterima - waktu paket dikirim

Persamaan untuk menghitung nilai delay ratarata dapat menggunakan persamaan berikut:

$$
\text { Delay rata }- \text { rata }=\frac{\text { total delay }}{\text { total paket dirim }}
$$

Ketegori capaian kinerja nilai delay untuk lebih

\begin{tabular}{|c|c|c|}
\hline $\begin{array}{c}\text { Kategori } \\
\text { Nilai }\end{array}$ & Kategori Hasil (ms) & Kategori Capaian \\
\hline 4 & $<150 \mathrm{~ms}$ & Excellent \\
\hline 3 & $150 \mathrm{~ms}-300 \mathrm{~ms}$ & Good \\
\hline 2 & $300 \mathrm{~ms}-450 \mathrm{~ms}$ & Medium \\
\hline 1 & $>450 \mathrm{~ms}$ & Poor \\
\hline
\end{tabular}
jelas lihat Tabel 2.

Tabel 2 Kategori capaian nilai Delay menurut Tiphon

\section{d. Jitter}

Jitter adalah sebuah delay variasi yang diterima pada antrian panjang paket data (Muhallim, 2017). Diketahui ada sebuah paket dikirim pada waktu detik ke 1, detik ke 2, detik ke 3, kemudian sampai ke tujuan dengan waktu detik ke 20, detik ke 29 dan detik ke 34. Pada setiap paket data yang dikirim ke tujuan terdapat nilai delay variasi. Nilai tersebut 
240 Jurnal Teknologi Informasi dan Ilmu Komputer (JTIIK), Vol. 8, No. 2, April 2021, hlm. 235-244

akhirnya disebut dengan nama jitter (Djatmika, 2019). Persamaan perhitungan jitter sebagai berikut:

$$
\text { Jitter }=\frac{\text { total variasi delay }}{\text { total paket yang diterima }}
$$

Ketegori capaian kinerja nilai jitter untuk lebih jelas lihat Tabel 3.

Tabel 3 Kategori capaian nilai jitter menurut Tiphon

\begin{tabular}{ccc}
\hline $\begin{array}{c}\text { Kategori } \\
\text { Nilai }\end{array}$ & Katergori Hasil (ms) & Ketogri Capaian \\
\hline 4 & $0 \mathrm{~ms}$ & Excellent \\
3 & $0 \mathrm{~ms}-75 \mathrm{~ms}$ & Good \\
2 & $75 \mathrm{~ms}-125 \mathrm{~ms}$ & Medium \\
1 & $125 \mathrm{~ms}-225 \mathrm{~ms}$ & Poor \\
\hline
\end{tabular}

\subsection{Hasil dan Penjabaran Parameter QoS}

Tahapan hasil dan pembahasan menjelaskan terkait hasil yang dilakukan setelah tahapan pemodelan topologi dan konfigurasi terhadap perangkat jaringan komputer, kemudian tahap berikutnya melakukan pengukuran terhadap kinerja routing yang sudah buat desain topologinya. Tabel 4 penelitian ini menunjukkan zona sampling atau perwakilan pengukuran dari beberapa Unit dan Fakultas yang mewakili intensitas keilmuan yang terkoneksi jaringan komputer.

Tabel 4 Zona Data Sampling Pengambilan Data

\begin{tabular}{|c|c|c|}
\hline No & $\begin{array}{c}\text { Nama } \\
\text { Kelompok/Zona }\end{array}$ & Lokasi Nama Gedung \\
\hline 1 & $\begin{array}{l}\text { Zona sampiling untuk } \\
\text { Unit/bagian }\end{array}$ & $\begin{array}{ll}- & \text { Rektorat Baru (REKB) } \\
- & \text { Laboratorium Terpadu } \\
& \text { (LABT) } \\
- & \text { Perpustakaan (LIBR) }\end{array}$ \\
\hline 2 & $\begin{array}{l}\text { Zona Sarjana Untuk } \\
\text { Fakultas Strata } 1\end{array}$ & $\begin{array}{ll}\text { - } & \text { Fak. Ilmu Sosial dan } \\
\text { Humaniora (ISOS) }\end{array}$ \\
\hline & & $\begin{array}{ll}\text { - } & \text { Fak. Sains dan } \\
\text { Teknologi (SAIN) } \\
\text { - } \quad \text { Fak. Ushuluddin dan } \\
\text { Pemikiran Islam } \\
\text { (USHU) }\end{array}$ \\
\hline 3 & \begin{tabular}{lrr} 
Zona & \multicolumn{2}{r}{ Program } \\
Magister Strata 2 & dan \\
Doktoral Strata & 3 \\
Pascasarjana &
\end{tabular} & $\begin{array}{l}\text { Pascasarjana Program } \\
\text { Magister dan Doktoral } \\
\text { (PASC) }\end{array}$ \\
\hline
\end{tabular}

Setelah terbentuk zona sampling zona sampling atau perwakilan pengukuran dari beberapa Unit dan Fakultas yang mewakili intensitas keilmuan yang terkoneksi jaringan komputer, selanjutnya dilakukan pengujian seperti pada yang telah dijelaskan pada metode penelitian pada peneltian ini. Gambar 4 adalah tampilan dari Command Line Interface yang ada pada aplikasi Command Prompt dan Gambar 5 adalah tampilan utama aplikasi wireshark.
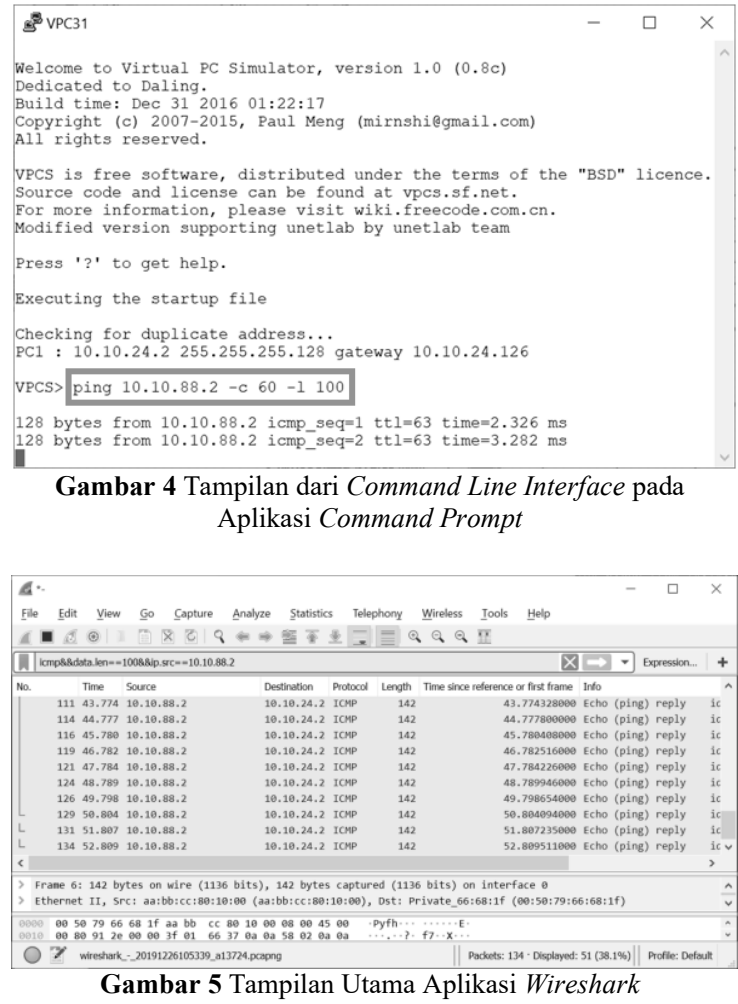

Tahapan selanjutnya adalah melakukan pengujian dan analisis hasil kinerja jaringan komputer berdasarkan parameter kriteria dari Quality of Services yang akan diteliti meliputi nilai throughput, nilai packet loss, nilai delay dan nilai jitter. Dengan hasil kinerja jaringan komputer sebagai berikut:

\section{a. Hasil dan Penjabaran Nilai Throughput}

Tabel 5 berikut adalah hasil dan analisis kinerja jaringan untuk parameter nilai throughput menggunakan skenario normal dan sibuk pada routing statik dan routing dinamis OSPF.

Tabel 5 Pengukuran nilai throughput untuk routing Statik dan

\begin{tabular}{|c|c|c|c|c|}
\hline \multirow{3}{*}{$\begin{array}{c}\text { Paket Data } \\
\text { ICMP } \\
\text { (Bytes) }\end{array}$} & \multicolumn{2}{|c|}{$\begin{array}{c}\text { Skenario Routing } \\
\text { Statik }\end{array}$} & \multicolumn{2}{|c|}{$\begin{array}{c}\text { Skenario Routing } \\
\text { Dinamis OSPF }\end{array}$} \\
\hline & Normal & Sibuk & Normal & Sibuk \\
\hline & $\begin{array}{c}\text { Rata- } \\
\text { rata }\end{array}$ & $\begin{array}{c}\text { Rata- } \\
\text { rata }\end{array}$ & $\begin{array}{c}\text { Rata- } \\
\text { rata }\end{array}$ & $\begin{array}{c}\text { Rata- } \\
\text { rata }\end{array}$ \\
\hline $0-100$ & 143,49 & 143,6 & 143,56 & 143,29 \\
\hline $100-200$ & 244,45 & 244,73 & 244,53 & 244,26 \\
\hline $200-300$ & 345,43 & 345,93 & 345,61 & 345,20 \\
\hline $300-400$ & 446,82 & 446,91 & 446,78 & 446,32 \\
\hline $400-500$ & 547,6 & 548,17 & 547,92 & 547,00 \\
\hline $500-600$ & 648,35 & 649,55 & 648,88 & 647,95 \\
\hline $600-700$ & 749,67 & 750,7 & 749,96 & 749,13 \\
\hline $700-800$ & 850.94 & 851,62 & 851,01 & 849,92 \\
\hline $800-900$ & 951,97 & 953,21 & 951,71 & 950,86 \\
\hline $900-1000$ & 1052,31 & 1053,82 & 1053,40 & 1051,89 \\
\hline $\begin{array}{l}\text { Total Nilai } \\
\text { Rata-rata }\end{array}$ & 598,10 & 598,82 & 598,34 & $\mathbf{5 9 7 , 5 8}$ \\
\hline
\end{tabular}




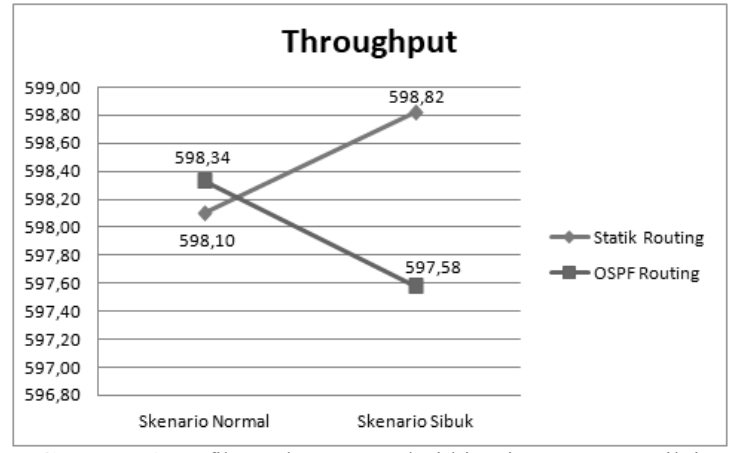

Gambar 6 Grafik total rata-rata dari kinerja parameter nilai throughput untuk routing Statik dan routing dinamis OSPF

Gambar 6 menyajikan Grafik data dari hasil untuk parameter nilai throughput pada skenario normal dan skenario sibuk untuk routing statik dan routing dinamis OSPF disajikan. Pada gambar tersebut menampilkan nilai total rata-rata parameter nilai throughput dihasilkan skenario normal oleh routing protokol statik lebih rendah daripada routing dinamis OSPF, sedangkan skenario sibuk nilai total rata-rata untuk routing statik lebih lebih tinggi daripada routing dinamis OSPF.

\section{b. Hasil dan Penjabaran Nilai Packet loss}

Tabel 6 berikut adalah hasil dan analisis kinerja jaringan untuk parameter nilai packet loss menggunakan skenario normal dan sibuk pada routing statik dan routing dinamis OSPF.

Tabel 6 Pengukuran nilai packet loss untuk routing Statik dan

\begin{tabular}{ccccc} 
& \multicolumn{2}{c}{ routing dinamis OSPF } \\
\hline \multirow{2}{*}{$\begin{array}{c}\text { Paket Data } \\
\text { ICMP } \\
\text { Bytes) }\end{array}$} & \multicolumn{2}{c}{$\begin{array}{c}\text { Skenario Routing } \\
\text { Statik }\end{array}$} & $\begin{array}{c}\text { Skenario Routing } \\
\text { Dinamis }\end{array}$ \\
\cline { 2 - 5 } & $\begin{array}{c}\text { Normal } \\
\text { Rata- } \\
\text { rata }\end{array}$ & $\begin{array}{c}\text { Rabuk } \\
\text { rata }\end{array}$ & $\begin{array}{c}\text { Rata- } \\
\text { rata }\end{array}$ & $\begin{array}{c}\text { Rata- } \\
\text { rata }\end{array}$ \\
\hline $0-100$ & 0,23 & 0,24 & 0,27 & 0,27 \\
$100-200$ & 0,24 & 0,24 & 0,27 & 0,26 \\
$200-300$ & 0,23 & 0,25 & 0,27 & 0,26 \\
$300-400$ & 0,23 & 0,24 & 0,27 & 0,26 \\
$400-500$ & 0,23 & 0,24 & 0,26 & 0,26 \\
$500-600$ & 0,23 & 0,24 & 0,27 & 0,26 \\
$600-700$ & 0,23 & 0,24 & 0,27 & 0,26 \\
$700-800$ & 0,23 & 0,24 & 0,27 & 0,26 \\
$800-900$ & 0,23 & 0,24 & 0,27 & 0,26 \\
$900-1000$ & 0,23 & 0,24 & 0,27 & 0,26 \\
\hline Total Nilai & $\mathbf{0 , 2 3}$ & $\mathbf{0 , 2 4}$ & $\mathbf{0 , 2 7}$ & $\mathbf{0 , 2 6}$ \\
Rata-rata & & & & \\
\hline
\end{tabular}

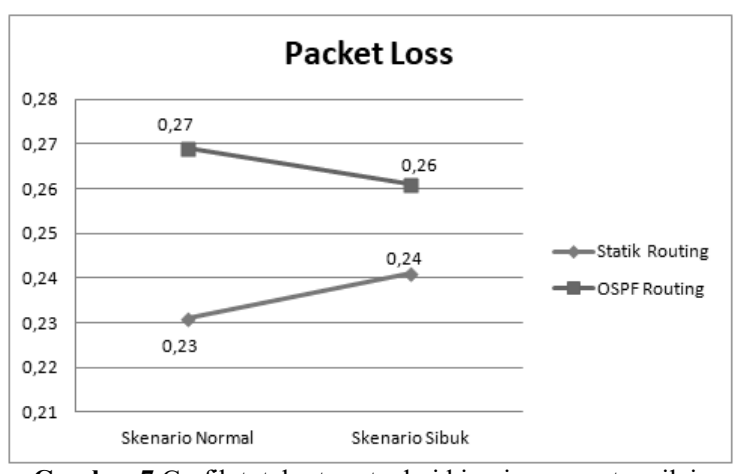

Gambar 7 Grafik total rata-rata dari kinerja parameter nilai packet loss untuk routing Statik dan routing dinamis OSPF
Gambar 7 menyajikan Grafik data dari hasil untuk parameter nilai packet loss pada skenario normal dan skenario sibuk untuk routing statik dan routing dinamis OSPF disajikan. Pada gambar tersebut menampilkan nilai total rata-rata untuk parameter dihasilkan oleh routing Statik lebih kecil dibandingkan routing dinamis OSPF.

\section{c. Hasil dan Penjabaran Nilai Delay}

Tabel 7 berikut adalah hasil dan analisis kinerja jaringan untuk parameter nilai delay menggunakan skenario normal dan sibuk pada routing statik dan routing dinamis OSPF.

Tabel 7 Pengukuran nilai delay untuk routing Statik dan routing dinamis OSPF

\begin{tabular}{|c|c|c|c|c|}
\hline \multirow{3}{*}{$\begin{array}{c}\text { Data Packet } \\
\text { ICMP } \\
\text { (Bytes) }\end{array}$} & \multicolumn{2}{|c|}{$\begin{array}{c}\text { Skenario Routing } \\
\text { Statik }\end{array}$} & \multicolumn{2}{|c|}{$\begin{array}{c}\text { Skenario Routing } \\
\text { Dinamis OSPF }\end{array}$} \\
\hline & Normal & Sibuk & Normal & Sibuk \\
\hline & $\begin{array}{c}\text { Rata- } \\
\text { rata }\end{array}$ & $\begin{array}{l}\text { Rata- } \\
\text { rata }\end{array}$ & $\begin{array}{l}\text { Rata- } \\
\text { rata }\end{array}$ & $\begin{array}{c}\text { Rata- } \\
\text { rata }\end{array}$ \\
\hline $0-100$ & 59,38 & 59,33 & 59,35 & 59,46 \\
\hline $100-200$ & 59,4 & 59,33 & 59,38 & 59,45 \\
\hline $200-300$ & 59,41 & 59,32 & 59,37 & 59,44 \\
\hline $300-400$ & 59,35 & 59,34 & 59,36 & 59,42 \\
\hline $400-500$ & 59,39 & 59,33 & 59,35 & 59,45 \\
\hline $500-600$ & 59,41 & 59,3 & 59,36 & 59,45 \\
\hline $600-700$ & 59,39 & 59,31 & 59,36 & 59,43 \\
\hline $700-800$ & 59,37 & 59,32 & 59,37 & 59,44 \\
\hline $800-900$ & 59,37 & 59,29 & 59,39 & 59,44 \\
\hline $900-1000$ & 59,41 & 59,33 & 59,35 & 59,44 \\
\hline $\begin{array}{l}\text { Total Nilai } \\
\text { Rata-rata }\end{array}$ & 59,39 & 59,32 & 59,36 & 59,44 \\
\hline
\end{tabular}

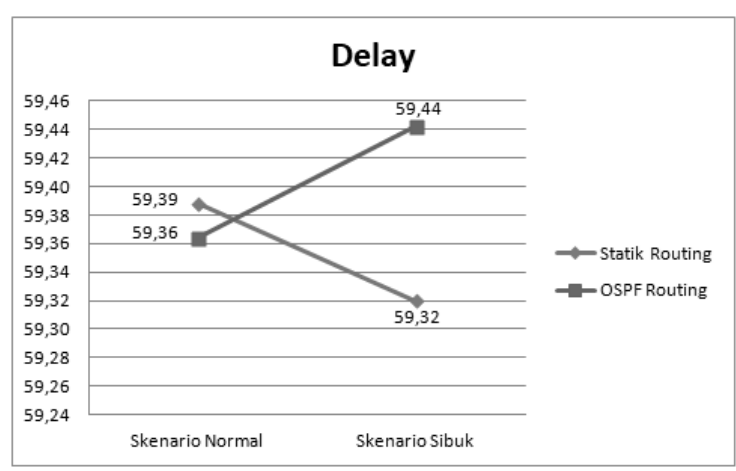

Gambar 8 Grafik rata-rata kinerja delay routing Statik dan routing dinamis OSPF

Gambar 8 menyajikan Grafik data dari hasil untuk parameter nilai delay pada skenario normal dan skenario sibuk untuk routing statik dan routing dinamis OSPF disajikan. Gambar tersebut menampilkan nilai total rata-rata yang dihasilkan menggunakan skenario normal oleh routing protokol statik lebih tinggi daripada routing dinamis OSPF, sedangkan skenario sibuk nilai total rata-rata untuk routing statik lebih lebih rendah daripada routing dinamis OSPF.

\section{d. Hasil dan Analisis Nilai Jitter}

Tabel 8 berikut adalah hasil dan analisis kinerja jaringan untuk parameter nilai jitter menggunakan skenario normal dan sibuk pada routing statik dan routing dinamis OSPF. 


\begin{tabular}{|c|c|c|c|c|}
\hline \multirow{3}{*}{$\begin{array}{c}\text { Data Packet } \\
\text { ICMP } \\
\text { (Bytes) }\end{array}$} & \multicolumn{2}{|c|}{$\begin{array}{c}\text { Skenario Routing } \\
\text { Statik }\end{array}$} & \multicolumn{2}{|c|}{$\begin{array}{c}\text { Skenario Routing } \\
\text { Dinamis OSPF }\end{array}$} \\
\hline & Normal & Sibuk & Normal & Sibuk \\
\hline & $\begin{array}{c}\text { Rata- } \\
\text { rata }\end{array}$ & $\begin{array}{l}\text { Rata- } \\
\text { rata }\end{array}$ & $\begin{array}{c}\text { Rata- } \\
\text { rata }\end{array}$ & $\begin{array}{l}\text { Rata- } \\
\text { rata }\end{array}$ \\
\hline $0-100$ & 0,98 & 0,98 & 0,98 & 0,99 \\
\hline $100-200$ & 0,98 & 0,98 & 0,98 & 0,99 \\
\hline $200-300$ & 0,98 & 0,98 & 0,98 & 0,99 \\
\hline $300-400$ & 0,98 & 0,98 & 0,98 & 0,99 \\
\hline $400-500$ & 0,98 & 0,98 & 0,98 & 0,99 \\
\hline $500-600$ & 0,98 & 0,98 & 0,98 & 0,99 \\
\hline $600-700$ & 0,98 & 0,98 & 0,98 & 0,99 \\
\hline $700-800$ & 0,98 & 0,98 & 0,98 & 0,99 \\
\hline $800-900$ & 0,98 & 0,98 & 0,98 & 0,99 \\
\hline $900-1000$ & 0,98 & 0,98 & 0,98 & 0,99 \\
\hline $\begin{array}{l}\text { Total Nilai } \\
\text { Rata-rata }\end{array}$ & 0,98 & 0,98 & 0,98 & 0,99 \\
\hline
\end{tabular}

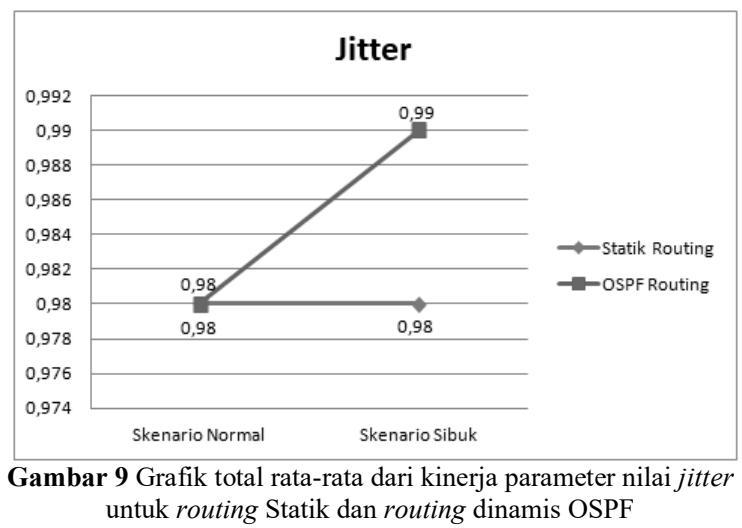

Gambar 9 menyajikan Grafik data dari hasil untuk parameter nilai jitter pada skenario normal dan skenario sibuk untuk routing statik dan routing dinamis OSPF disajikan. Pada gambar tersebut menampilkan nilai total rata-rata untuk parameter dihasilkan oleh routing statik menggunakan skenario normal yang sama dengan routing dinamis OSPF. Namun pada skenario sibuk routing statik lebih rendah dibanding routing dinamis OSPF dengan selisih nilai $0,01 \mathrm{~ms}$.

\section{KESIMPULAN}

Kesimpulan yang dapat dirangkum dari penelitian ini, antara lain:

1. Perbandingan kinerja routing statik pada parameter throughput untuk skenario normal nilai total rata-rata routing statik sebesar 598,10Bps dan skenario sibuk sebesar 598,82Bps. Sedangkan routing dinamis OSPF untuk skenario normal sebesar 598,34Bps dan skenario sibuk sebesar 597,58Bps. Berdasarkan indeks nilai parameter dari TIPHON menunjukkan semakin tinggi nilai throughput berarti semakin optimal dan baik, maka routing statik lebih optimal dibandingkan routing dinamis OSPF pada skenario sibuk.

2. Perbandingan kinerja routing statik pada parameter packet loss untuk skenario normal nilai total rata-rata routing statik sebesar $0,23 \%$ dan skenario sibuk sebesar $0,24 \%$. Sedangkan routing dinamis OSPF untuk skenario normal sebesar $0,27 \%$ dan skenario sibuk sebesar $0,26 \%$. Berdasarkan indeks nilai parameter dari TIPHON semakin kecil nilai packet loss berarti semakin optimal dan baik, maka routing statik lebih optimal dibandingkan routing dinamis OSPF pada semua skenario pengujian.

3. Perbandingan kinerja routing statik pada parameter delay untuk skenario normal nilai total rata-rata routing statik sebesar $59,39 \mathrm{~ms}$ dan skenario sibuk sebesar 59,32 ms. Sedangkan routing dinamis OSPF untuk skenario normal sebesar $59,36 \mathrm{~ms}$ dan skenario sibuk sebesar 59,44ms. Berdasarkan indeks nilai parameter dari TIPHON menunjukkan semakin kecil nilai delay berarti semakin optimal dan baik, maka routing statik lebih optimal dibandingkan routing dinamis OSPF pada skenario sibuk.

4. Perbandingan kinerja routing statik pada parameter jitter untuk skenario normal nilai total rata-rata routing statik sebesar $0,98 \mathrm{~ms}$ dan skenario sibuk sebesar 0,98ms. A1Sedangkan routing dinamis OSPF untuk skenario normal sebesar 0,98ms dan skenario sibuk sebesar $0,99 \mathrm{~ms}$. Berdasarkan indeks nilai parameter dari TIPHON semakin kecil nilai jitter berarti semakin optimal dan baik, maka routing statik lebih optimal dibandingkan routing dinamis OSPF pada semua skenario pengujian.

5. Sebuah pengiriman paket data tidak dapat dinilai secara mutlak karena besar kecil pengiriman tergantung besar paket yang dikirim dan lamanya respon waktu penerimaan paket tersebut.

\section{DAFTAR PUSTAKA}

ARDIAN, Y., \& SETIYANINGSIH, W. (2014). Optimasi Static Routing pada Intranet Memanfaatkan Load Balancing Menggunakan Mikrotik-OS. (Tulus, M. Ramli, M. H. Zulfin, S. Sembiring, Irvan, U. Khair, \& I. Lubis, Eds.) (2nd ed.). Medan: Sekolah Tinggi Teknik Harapan Medan. Retrieved from http://repository.unikama.ac.id/id/eprint/217

ARDYANSAH, S., IRFAN A, L. A. S., \& RACHMAN, A. S. (2018). Perancangan dan Simulasi dari Kombinasi Routing Statik dan Routing Dinamis Pada Routing Protokol $O S P F$. Universitas Mataram. Retrieved from http://eprints.unram.ac.id/id/eprint/6204

ARGENTA, L. R. (2016). Analisis Unjuk Kerja RIP dan OSPF pada Topologi Sederhana dan Topologi Kompleks. Universitas Sanata Dharma Yogyakarta. Retrieved from https://repository.usd.ac.id/6297/2/105314085 full.pdf

DJATMIKA, F. W. (2019). Komparasi Metode 
PPTP dan L2TP/IPSEC Pada MikroTik Router. Universitas AMIKOM Yogyakarta.

ETSI. (1999). Telecommunications and Internet Protocol Harmonization Over Networks (TIPHON); General aspects of Quality of Service (QoS), 2.1.1, 1-37. Retrieved from http://www.etsi.org/deliver/etsi tr/101\%0A30 0_101399/101329/02.01.01_60/tr_101329\%0 Av020101p.pdf

GATRA, R., AKBAR, R., SUGIANTORO, B., \& ASYHAB, N. (2019). VLAN-based LAN Network Management Comparison using Cisco and Brocade. IJID (International Journal on Informatics for Development), 7(2), 47-51. https://doi.org/http://dx.doi.org/10.14421/ijid. 2018.07208

ISKANDAR, I., \& HIDAYAT, A. (2015). Analisa Quality of Service (QoS) Jaringan Internet Kampus (Studi Kasus: UIN Suska Riau). Jurnal CoreIT, 1(2), 67-76. Retrieved from http://ejournal.uin-

suska.ac.id/index.php/coreit/article/view/1233 $/ 1112$

KUSUMA, A. C. (2017). Analisis Perbandingan Quatity of Service (QoS) Pada Radio Streaming Server dengan Variasi Bitrate. Universitas Muhammadiyah Malang. Retrieved from http://eprints.umm.ac.id/36079/3/jiptummppgdl-adhichandr-47933-3-4.babii.pdf

MUHALLIM, M. (2017). Pengembangan Jaringan Komputer Universitas Andi Djemma Palopo Berdasarkan Perbandingan Jaringan Protokol Routing Statik dan OSPFv2, 2, 89-99.

SUGIANTORO, B. (2017). Pengembangan Deteksi Penyusupan Menggunakan Multiagent. Telematika, 14(2), 83-88. https://doi.org/10.31315/telematika.v14i2.209 5

SULAIMAN, O. K., \& IHWANI, M. (2017). Analisis Perbandingan Penggunaan Metric Cost dan Bandwidth Pada Routing Protocol OSPF. Jurnal \& Penelitian Teknik Informatika, 1(April), 7-12. Retrieved from https://jurnal.polgan.ac.id/index.php/sinkron/a rticle/view/28/7

ULFA, M., \& FATONI. (2017). Analisis Perbandingan Penerapan Static Routing Pada Ipv4 Dan Ipv6. Jurnal Ilmiah MATRIK, 19(2), 177-186. Retrieved from https://media.neliti.com/media/publications/2 81645-analisis-perbandingan-penerapanstatic-r-df1 f3061.pdf 
Halaman ini sengaja dikosongkan 